4. Smith B., Oh l s on R., Acta Chem. Scand., 14, 1317 (1960).

5. Березкин В. Г., Аналитическая реакционная газовая хроматография, М., 1966.

6. Салусте С., Клесмент И., Э йзен О., Изв. АН ЭССР, Сер. физ.-матем. и техн. н., 14, 605 (1965).

7. Баландин А. А., Современное состояние мультиплетной теории гетерогенного катализа, М., 1968.

8. Казанский Б. А., Ли берман А. Л., Платэ А. Ф., Докл. АН СССР, 57, 571 (1947)

9. Ранг С, Эйзен О., Кунинга С., Изв. АН ЭССР, Хим. Геол., 17, 217 (1968)

Ннститут химии

Академии каук Эстонской ССР
Поступила в редакцию 23 IV 1971

EESTI NSV TEADUSTE AKADEEMIA TOIMETISED. 21. KOIDE

KEEMIA * GEOLOOGIA. 1972, NR, 1

ИЗВЕСТИЯ АКАДЕМИИ НАУК ЭСТОНСКОИ ССР. ТОМ 21

Химия * ГЕология, 1972, № 1

A. ИВАНОВ, О. ЭИЗЕН, А. ЯГОМЯГИ

\title{
ИССЛЕДОВАНИЕ ОКИСЛЕНИЯ УГЛЕВОДОРОДОВ И ОКИСИ УГЛЕРОДА НА ПЛАТИНОВОМ КАТАЛИЗАТОРЕ
}

A. IVANOV, O. EISEN, A. JAGOMAGI. SUSIVESINIKE JA SUSINIKMONOOKSIIDI OKSUDEERIMINE PLAATINAKATALUSAATORIL

1. IWANOW, O. EISEN, A. JAGOMAGI. OXIDATION DER KOHLENWASSERSTOFFE UND DES KOHLENMONOOXIDS AN EINEM PLATINKATALYSATOR

Проведение дегидрогенизационного катализа с применением микро реакторно-газохроматографической техники в токе инертного газа-носигеля (гелия) обусловливает вследствие коксообразования быстрое падение активности катализаторов [']. Поэтому для анализа шестичленных нафтенов дегидрогенизацию целесообразнее проводить в токе водорода. Тем не менее изучение таких процессов, как хемосорбция кислорода на платине [2], коксообразование [3] или перераспределение водорода между молекулами циклогексенов или циклопентенов [4, 5] можно проводить и в атмосфере инертного газа.

Для восстановления активности платиновые катализаторы подвер гают обычно обработке кислородом воздуха при $300-500^{\circ} \mathrm{C}$, обеспечивающей полное удаление кокса. В этих условиях параллельно с окислением кокса до $\mathrm{CO}_{2}$ и $\mathrm{H}_{2} \mathrm{O}$ протекает хемосорбция кислорода, степень которой зависит от температуры регенерирования [6, 7].

Если катализатор после регенерирования подвергнуть хотя б́ы кратковременной обработке водородом (для удаления кислорода), то вследствие растворения водорода в платине результаты экспериментов с углеводородами будут аналогичными с результатами опытов, проводимых в токе водорода до тех пор, пока водород не будет полностью использован. 
Если катализатор не обрабатывать водородом, то присутствие хемосорбированного кислорода обусловливает при введении импульсов углеводородов протекание окислительных реакций.

Полное окисление углеводородов можно выразить уравнением

$$
\mathrm{C}_{n} \mathrm{H}_{2 m}+\left(n+\frac{m}{2}\right) \mathrm{O}_{2}=n \mathrm{CO}_{2}+m \mathrm{H}_{2} \mathrm{O} \text {. }
$$

Однако в определенных условиях возможно также неполное окисление углеводородов с образованием СО:

$$
\begin{aligned}
(m+n) \mathrm{MeO}+\mathrm{C}_{n} \mathrm{H}_{2 m} & =(m+n) \mathrm{Me}+n \mathrm{CO}+m \mathrm{H}_{2} \mathrm{O} \\
\mathrm{C}_{n} \mathrm{H}_{2 m}+n \mathrm{H}_{2} \mathrm{O} & =n \mathrm{CO}+(m+n) \mathrm{H}_{2} .
\end{aligned}
$$

При этом не исключается также дальнейшее полное окисление окиси углерода

$$
\mathrm{CO}+\mathrm{H}_{2} \mathrm{O}=\mathrm{CO}_{2}+\mathrm{H}_{2} \text {. }
$$

Присутствие в катализате $\mathrm{CO}_{2}$ при введении импульсов углеводородов на регенерированный катализатор было усгановлено на основании качественной реакции с $\mathrm{Ba}(\mathrm{OH})_{2}\left[^{1}\right]$. В литературе [8] имеются сообщения о присутствин в катализатах углеводородов на катализаторах платиновой группы некоторого количества СО.

Исследование состава газообразных продуктов катализатов некото рых углеводородов, полученных на платино-силикагелевом катализаторе, проведенное на специально подготовленной для этой цели силикагелевой колонке, не подтвердило это, углеводороды полностью окислялись до $\mathrm{CO}_{2}$.

Полученные результаты хотя и не исключают возможности образо вания СО в видоизмененных условиях, однако находятся в согласии с данными М. Славинского [], по которому присутствне платины способствует полному окислению углевсдородов.

Для выяснения влияния платины на окислительные процессы иссле довали реакции окиси углерода в аналогичных условиях. В результате введения импульсов $\mathrm{CO}$ на регенерированном катализаторе происходило окисление с образованием двуокиси углерода.

Течение реакции окисления СО представлялось возможным по двум механизмам.

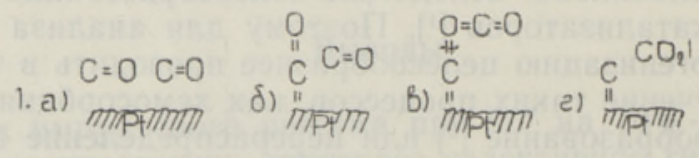

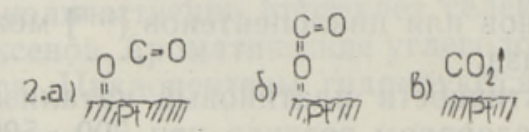

По первому механизму окисление СО происходит в результате перераспределения кислорода между молекулой адсорбированного на поверх ности платины $\mathrm{CO}$ и молекулой $\mathrm{CO}$, находящейся в газовой фазе. Про текание реакции по этому механизму может быть результатом ослабления связи между атомом углерода и кислорода у молекулы СО, адсорбированной на платине, а также следствием сильного восстанавливающего свойства и склонности окиси углерода к реакциям присоединения. 
По второму механизму предполагается участие в реакции окисления кислорода, хемосорбированного на поверхности или в ближайших $\mathrm{k}$ поверхности слоях платины. Чтобы устранить влияние последнего на окисление СО, было проведено два варианта экспериментов.

По первому варианту в микрореактор вводили ряд последовательных импульсов углеводородов, интенсивно образующих кокс [3] (например 1-метилциклопентен-1, циклогексен), до полного удаления хемосорбированного кислорода, что выражалось в прекращении появления пиков $\mathrm{CO}_{2}$ на хроматограмме. При последующем введении импульсов $\mathrm{CO}$ на хроматограмме вновь регистрировались пики $\mathrm{CO}_{2}$, образование которого хотя и могло быть объяснено окислением СО в результате перераспределения кислорода, однако все же полностью не давало гарантии отсутствия хемосорбированного кислорода. В то же время постепенное уве личение степени конверсии $\mathrm{CO}$ в $\mathrm{CO}_{2}$ свидетельствовало о большей вероятности автоокисления СО, протекающего в присутствии платины.

Второй вариант опытов предусматривал полное удаление хемосорбированного кислорода путем восстановления платины в течение 2 в токе водорода и дальнейшей 2-часовой обработки гелием при 300 и $350^{\circ}\left[{ }^{7}\right]$. После введения первого импульса $\mathrm{CO}$ образования $\mathrm{CO}_{2}$ не наблюдалось. При введении последующих импульсов было отмечено появление постепенно увеличивающихся пиков $\mathrm{CO}_{2}$, которые после введения 10-12 импульсов достигали максимального значения и после чего постепенно уменьшались. Следует отметить, что степень конверсии СО в опытах при $300^{\circ}$ была выше, чем при $350^{\circ}$, что, очевидно, объясняется уменьшением адсорбции окиси углерода с повышением температуры.

Таким образом, результаты опытов, проводившихся в условиях полного восстановления платины и исключающих возможность присутствия хемосорбированного кислорода, подтверждают каталитическое свойство платины способствовать образованию $\mathrm{CO}_{2}$ в результате перераспределения кислорода.

Интересно отметить, что при введении импульсов СО в токе водорода наблюдалась реакция, аналогичная известной реакции Фишера-Тропша, протекающая с образованием метана:

$$
\mathrm{CO}+3 \mathrm{H}_{2} \underset{\mathrm{Pt}}{\stackrel{30 \mathrm{O}-350^{\circ}}{\longrightarrow}} \mathrm{CH}_{4}+\mathrm{H}_{2} \mathrm{O} .
$$

Степень конверсии СО при постоянных температуре и скорости газа-носителя оставалась неизменной, так как не зависела от числа импульсов. С повышением температуры выход метана увеличивался.

\section{Экспериментальная часть}

Опыты проводились на двухколоночном газовом хроматографе типа УХ, первая колонка которого была заменена микрореактором, заполненным 2 мл $5 \%$-ного платинового катализатора, нанесенного на силикагель ШСК. Температура микрореактора 300 и $350^{\circ}$. Идентификацию газооб. разных компонентов производили на 1 колонке, заполненной силиқагелем ACM (0,25-0,315 мм), при температуре $20^{\circ}$. Скорость газа-носителя гелия $50 \mathrm{мл/мин.}$

Окись углерода получали из муравьиной кислоты по [9]. Исследование газообразных продуктов катализата проводилось с применением газохроматографически чистых циклогексана, бензола, метилбензола, метилциклогексана, циклогексена, 1-метилциклогексена-1, 1-аллилциклогексена-1 и 1-метилциклопентена-1. 


\section{Выводы}

1. Импульсным методом в токе гелия исследовались продукты окисления углеводородов на платине. В выбранных для опытов условиях единственным продуктом окисления являлась $\mathrm{CO}_{2}$.

2. При полном отсутствни хемосорбнрованного кислорода на восстановленном платиновом катализаторе в токе гелия наблюдается автоокисление окиси углерода.

3. В токе водорода на платине наблюдается конверсия СО до метана.

\section{I ИTЕ Р А Т У Р A}

1. Ив а нов А., Эй зен. О., Изв. АН ЭССР, Хим. Геол., 18, 218 (1969).

2 Эй зен Н О., Ив а нов А., Изв. АН ЭССР, Хим. Геол., 18, 85 (1969).

3. Ив а нов А., Э й $з$ ен О., Изв. АН ЭССР, Хим. Геол., 18, 353 (1969).

4. Э йзен О., Ив а нов А., Ягомяги А., Изв. АН ЭССР, Хим. Геол., 20, 187 (1971).

5 Шимулис В. И., Сальданя А. Р., Кинетика и катализ, 8, 125 (1967).

6. С л а в и н ски й $M$. П., Физико-химические свойства элементов, М., 1952, с. 658.

7. We i d e n b a ch G., F ür si H., Chem. Technik, 15, 589 (1963).

8. Д ыдыкина Г. В., Р а бинович Г. Л., В сб.: Успехн газовой хроматографии, вып. 2, Казань, 1970, с. 138.

9. P a r i s A., Keemilise analüüsi praktikum, Tartu, 1941, lk. 215.

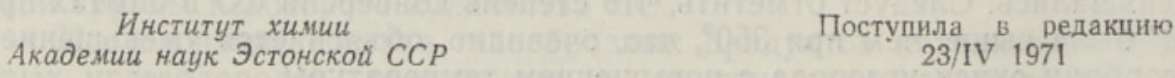

EESTI NSV TEADUSTE AKADEEMIA TOIMETISED. 21. KOIDE

KEEMIA * GEOLOOGIA. 1972, NR. 1

ИЗВЕСТИЯ АКАДЕМИИ НАУК ЭСТОНСКОИ ССР. ТОМ 21

ХИМИя - ГЕОЛОГИя. 1972, № 1

УДК $547.56 ; 541.127 ; 628.356$

\section{Н. БЕРНОВСКАЯ, УУВЕ КИРСО, М. ГУБЕРГРИЦ}

\section{КИНЕТИКА БИОХИМИЧЕСКОГО ОКИСЛЕНИЯ ФЕНОЛОВ НА ИЛЕ, АДАПТИРОВАННОМ К 5-МЕТИЛРЕЗОРЦИНУ}

N. BERNOVSKAJA, UUVE KIRSO, M: GUBERGRITS. FENOOLIDE BIOKEEMILISE OKSUDEERI. MISE KINEETIKA 5-METOULRESORTSIINILE ADAPTEERITUD AKTIIVMUDAL

N. BER.NOVSKAYA, UUVE KIRSO, M. GUBERGRITS. THE KINETICS OF PHENOLS BIOCHEMICAL. OXIDATION ON MUD ADAPTED TO 5-METHYLRESORCINOL

Биохимическое окисление алкилпроизводных резорцина активным илом, адаптированным к оксибензолу или резорцину, протекает чрезвычайно медленно и неравномерно $\left[{ }^{1,2}\right]$. Отмеченное нами некоторое уско рение их деградации при адаптации ила к смеси «сланцевых» феноло5 сложного строения из промышленного стока $\left[{ }^{2}\right]$ дает основание для поста. новки дополнительного эксперимента с илом, адаптированным к одному 